\title{
Vivências de mulheres à dor no infarto do miocárdio*
}

\author{
EXPERIENCES OF WOMEN IN FACE OF PAIN FROM ACUTE MYOCARDIAL INFARCTION
}

VIVENCIAS DE MUJERES FRENTE AL DOLOR EN EL INFARTO DEL MIOCARDIO

\author{
Fernanda Carneiro Mussi ${ }^{1}$, Sílvia Lúcia Ferreira ${ }^{2}$, Angélica Araújo de Menezes ${ }^{3}$
}

* Estudo integrante do
projeto de pesquisa
"Compreensão do
significado da dor
como sintoma
prodrômico do
infarto agudo do
miocárdio: vivências
da clientela para
ações imediatas"
desenvolvido com
apoio da Fundação
de Amparo a Pes-
quisa do Estado da
Bahia/ Ministério da
Saúde/Decit/ Secre-
taria do Estado da
Bahia e PIBIC-CNPq-
Universidade Fede--
ral da Bahia (UFBA).
1 Doutora. Professora
do Departamento de
Enfermagem Médi-
co-Cirúrgica e Admi-
nistração em Enfer-
magem da Escola de
Enfermagem da UFBA.
2 Doutora. Professora
do Departamento de
Enfermagem Comu-
nitária da UFBA.
Pesquisadora do -
Grupo de Estudos
sobre Saúde da
Mulher (GEM).
silvialf@ufba.br
duação em enfer-
magem. Bolsista de
Iniciação Científica
(PIBIC/UFBA),
Orientada pela
Professora Fernanda
Carneiro Mussi.
geomenezes@yahoo.combr

\section{RESUMO}

O estudo objetivou compreender os significados da experiência da dor em mulheres que sofreram infarto do miocárdio e identificar as suas ações imediatas diante da mesma. A pesquisa qualitativa utilizou a teoria do Interacionismo Simbólico e a metodologia da Teoria Fundamentada nos Dados. Quarenta e três mulheres foram entrevistadas em Hospital Universitário. A categoria central que expressou o sentido da experiência foi "Tendo uma ruptura com a vida cotidiana". As categorias que revelaram essa ruptura mostraram que diante da dor crescente as mulheres se sentiram dominadas e com medo de morrer, pois perderam o controle pessoal sobre o corpo e a vida. Não reconheceram o infarto e resistiram, a princípio, à procura de atendimento, fazendo tentativas para minorar a dor. Interagindo com a dor insuportável e com a impotência no seu controle, pediram a salvação Divina, ajuda às pessoas e recorreram a tratamento médico.

\section{DESCRITORES}

Infarto do miocárdio.

Dor no peito.

Mulheres.

\section{ABSTRACT}

The aim of this study was to understand the meanings of the experience of pain suffered by women during acute myocardial infarction (AMI) and to identify their immediate actions in face of pain. This qualitative research used the Symbolic Interactionism theory and the Grounded Theory methodology. Forty-three women were interviewed at the University Hospital. The central category expressing the pain experience was that it was "a break with day-to-day life". The categories that expressed such break revealed that in face of increasing pain those women felt dominated and afraid of dying because they had lost control over their bodies and their lives. They did not recognize the occurrence of AMI and at first resisted to look for assistance by attempting to alleviate the pain. In face of the unbearable pain and their impotence to control it, they asked for God's salvation and help from surrounding people and finally resorted to medical assistance.

\section{KEY WORDS}

Myocardial infarction.

Chest pain.

Women.

\section{RESUMEN}

En el presente estudio se tuvo como objetivo comprender los significados de la experiencia del dolor en mujeres que sufrieron infarto del miocardio e identificar sus acciones inmediatas frente a la misma. En esta investigación cualitativa se utilizó la teoría del Interaccionismo Simbólico y la metodología de la Teoría Fundamentada en los Datos. Fueron entrevistadas cuarenta y tres mujeres del Hospital Universitario. La categoría central que expresó el sentido de la experiencia fue "Teniendo una ruptura con la vida cotidiana". Las categorías que revelaron esa ruptura mostraron que frente al creciente dolor las mujeres se sintieron dominadas y con miedo de morir, pues perdieron el control personal sobre el cuerpo y la vida. No reconocieron el infarto y se resistieron, al principio, a procurar atención, haciendo intentos para aminorar el dolor. Ante el dolor insoportable y la impotencia en su control, pidieron la salvación Divina, ayuda a las personas y recurrieron al tratamiento médico.

\section{DESCRIPTORES}

Infarto del miocardio.

Dolor de pecho

Mujeres. 


\section{INTRODUÇÃO}

As doenças cardiovasculares - que incluem o infarto agudo do miocárdio (IAM) - representam uma das principais causas de mortalidade e morbidade. No Brasil, na primeira metade da década de 90 , representavam $30 \%$ do total das mortes. Por outro lado, as doenças isquêmicas do coração, no período de 1993 e 1997, responderam por 1\% do total das causas de internação pelo SUS no país, o que, embora possa estar subestimado, ainda é muito significativo ${ }^{(1)}$. Dentre estas, o IAM, recente ou antigo, constituiu $27 \%$ dos motivos das quase 700 mil internações por doenças isquêmicas do coração ocorridas naquele período. Três estudos realizados em Salvador mostraram incidência estimada por IAM - 99/100.000 adultos com idade maior ou igual a 25 anos $^{(2)}$. A letalidade hospitalar do IAM foi $14,6 \%$ e que o risco de morrer vivenciado pelas mulheres hospitalizadas por IAM é mais de duas vezes maior que o dos homens ${ }^{(3)}$.

Apesar da expressiva redução da letalidade hospitalar do IAM, decorrente da introdução de novas tecnologias, como o advento das unidades coronarianas, uso de agentes fibrinolíticos, da aspirina e betabloqueadores e, mais recentemente, da angioplastia coronária primária, a questão da mortalidade pré-hospitalar permanece praticamente inalterada, com níveis semelhantes aos de 40 anos atrás, desafiando as autoridades de saúde pública e ceifando milhares de vidas em plena idade produtiva, acarretando inúmeros prejuízos à sociedade ${ }^{(4)}$.

Sabe-se que dois terços das mortes súbitas por doenças coronarianas ocorrem fora do hospital e a maioria dentro de duas horas após o início dos sintomas cardiovasculares, cuja causa mais frequiente é a fibrilação ventricular. A mortalidade pode ser minimizada se as pessoas receberem atendimento rápido após o início dos sintomas ${ }^{(5)}$. Todavia um obstáculo importante para o benefício da terapia de reperfusão coronariana continua sendo o atraso na instituição da mesma. É sabido que pelo menos $60 \%$ das pessoas que sofrem IAM apresentam sinais e sintomas prodrômicos, mas nem todos os reconhecem e/ou hesitam em aceitar a gravidade de sua condição, retardando, assim, o recurso ao socorro médico ${ }^{(5-7)}$. Portanto um dos grandes desafios no esforço de reduzir a mortalidade por infarto e minimizar seus danos físicos, psicológicos e sociais é reconhecer o motivo do retardo pré-hospitalar (período decorrido entre o início dos sintomas e a chegada ao hospital) para, então, promover a valorização por parte dos pacientes da busca de tratamento médico precoce. Assim, atender a esse desafio requer, entre outros aspectos, a compreensão pelos profissionais de saúde do significado da experiência da dor em mulheres com histórico de ataque cardíaco, bem como a identificação de suas ações imediatas frente à dor e aos sintomas associa- dos para, posteriormente, envidar-se esforços no desenvolvimento de atividades educativas.

Com base no exposto, foram objetivos deste estudo:

- Compreender os significados da experiência da dor para mulheres que sofreram infarto agudo do miocárdio;

- Identificar as ações imediatas dessas mulheres frente à dor.

\section{BASES TEÓRICO-METODOLÓGICAS}

Trata-se de um estudo descritivo exploratório que empregou a metodologia da Teoria Fundamentada nos Dados ${ }^{(8)}$ e utilizou a perspectiva teórica do Interacionismo Simbóli$\mathrm{co}^{(9)}$. As premissas básicas desta teoria permitem entender que:

1) O significado das coisas (objetos físicos, outros seres humanos, instituições, idéias, situações da vida cotidiana) resulta ou emerge da interação social que os seres humanos estabelecem uns com os outros. Sendo produtos sociais derivados das interações, os significados não são inerentes à coisa em $\mathrm{si}^{\left({ }^{(9)}\right.}$.

2) Os significados são manipulados e modificados pelo ser humano, por meio de um processo interpretativo usado por ele quando lida com as coisas que encontra. A interpretação não é uma mera aplicação automática dos significados estabelecidos, mas um processo formativo, no qual os significados são usados e revisados como instrumentos para guiar e formar a ação. Para tal, o processo interpretativo ocorre em duas etapas. Primeiro, a pessoa aponta para si as coisas em relação às quais está agindo, ou seja, a que atribui significado. Fazer tais indicações é um processo internalizado, no qual a pessoa está interagindo, comunicando, conversando consigo mesma. Na segunda fase, e mediante o processo de comunicação consigo mesma, a pessoa seleciona, verifica, suspende, reagrupa e transforma os significados aplicados à luz da situação em que se encontra ${ }^{(9)}$.

3) Os seres humanos agem em relação às coisas (objetos físicos, outros seres humanos, instituições, idéias, situações da vida cotidiana) com base nos significados que elas têm para eles. Considerando-se que tais significados influenciam a formação do comportamento da pessoa, o seu conhecimento pode levar à compreensão do agir humano ${ }^{(9)}$.

O método de investigação escolhido foi o da Teoria Fundamentada nos Dados (Grounded Theory). Essa metodologia de coleta e análise sistemática de dados qualitativos permite detectar processos psicossociais e desenvolver modelos teóricos de fenômenos da realidade empírica $^{(8)}$. 
O estudo foi realizado em Hospital Universitário, situado em Salvador-BA, com mulheres adultas, em condições de serem entrevistadas, que sofreram IAM com dor e que demandou atendimento médico. O número de mulheres não foi predeterminado, mas resultante do processo de amostragem teórica, um dos procedimentos da Teoria Fundamentada nos $\operatorname{Dados}^{(8)}$. Nessa abordagem, a coleta e análise são entrelaçadas e ocorrem simultaneamente, já que a análise vai dirigindo o processo de amostragem. A preocupação é com a representatividade das categorias-conceitos que emergem do discurso dos sujeitos, de modo a acumular evidências e dar maior densidade ao fenômeno em estudo. Então, o número de participantes resultou da representatividade dos conceitos que emergiram. Após as entrevistas com $43 \mathrm{mu}-$ lheres, a saturação teórica das categorias foi alcançada, isto é, verificou-se a repetição de dados e a ausência de dados novos e, paralelamente, ocorreu a crescente compreensão dos conceitos identificados ${ }^{(8)}$.

Para a coleta de dados, realizada no período de dezembro 2003 a junho de 2004, foi elaborado um formulário contendo, na primeira parte, dados de identificação das mulheres e, na segunda, questões abertas e semi-estruturadas que visaram a atender aos dois objetivos desta investigação, conforme segue: Fale-me sobre a dor que você sentiu; O que você fez na hora da dor?; O que você pensou?; O que você sentiu? A entrevista foi gravada nas unidades de internação e coronariana e no ambulatório de um Hospital Universitário. Os dados das questões abertas e semi-estruturadas foram transcritos na íntegra. Mediante assinatura do consentimento livre e esclarecido, as participantes concordaram em participar da pesquisa. Foi-lhes assegurado o esclarecimento dos objetivos da investigação, o sigilo da identidade pessoal e o direito de abandonar o estudo, se julgassem necessário.

Os dados de caracterização das participantes foram analisados com base em números absolutos e índices percentuais; os referentes às questões abertas e semiestruturadas, com base no referencial teórico e mediante emprego de três tipos de codificação da Teoria Fundamentada em Dados. Na primeira fase da análise dos dados, as respostas foram examinadas minuciosamente, linha por linha, para extrair os primeiros códigos. Pelo processo de comparação, os códigos identificados foram agrupados por similaridades e diferenças, formando as categorias. Com o avanço da análise, as categorias foram construídas, recodificadas, combinadas e comparadas entre si. Na última fase, buscou-se identificar a categoria central, determinando-se e validando-se sua relação com as outras categorias e destas entre si. A categoria central é o elo de ligação entre todas as demais ${ }^{(8)}$.

\section{RESULTADOS E DISCUSSÃO}

\section{O perfil sócio demográfico das entrevistadas}

Das quarenta e três entrevistadas, apenas oito encontravam-se na faixa etária jovem, para exposição ao IAM, ou seja, até 45 anos. Todas as outras trinta e cinco $(81,4 \%)$, estavam acima de 50 anos, confirmando os estudos já realizados sobre a incidência de infarto em mulheres ${ }^{(10)}$. Conforme descrito, a pesquisa foi realizada em hospital universitário, que possui um excelente aporte tecnológico e de pessoal para o atendimento cardiológico. Sua clientela é prioritariamente do SUS, proveniente da capital e de outras regiões da Bahia, pertencente às camadas populares. Nas faixas etárias acima de 50 anos, a maioria das mulheres já está sozinha, por morte dos companheiros ou separação, e com pouca possibilidade de refazer a sua vida conjugal. Neste estudo, foram encontradas vinte e cinco $(58,1 \%)$ nesta situação (solteiras, viúvas e separadas) e apenas três não possuíam filhos. Como era de se esperar, as mulheres nascidas entre as décadas de 1930 e 1960, possuem uma maior quantidade de filhos, já que a fecundidade no Brasil começou a decrescer na década de 1980, chegando atualmente a 2,3 filhos por mulher. Trinta e uma mulheres $(72,1 \%)$ possuíam de 3 até 10 filhos. A escolaridade baixa foi característica da maioria delas, pois trinta e uma $(72,1 \%)$ ou eram analfabetas ou não possuíam o primeiro grau completo. Salienta-se que vinte e duas $(51,1 \%)$ não exerciam atividade profissional por serem aposentadas, pensionistas ou afastadas pelo INSS. O fato de estarem nesta condição não as isentava de trabalho doméstico ou de realizar outras atividades, contribuindo para aumentar a renda familiar que se caracterizou como baixa - entre 1 a 3 salários mínimos - para mais da metade das mulheres. As ocupações desempenhadas por elas foram aquelas que podem ser caracterizadas ou pela esfera doméstica ou pelo prolongamento desta ao âmbito público, a exemplo de: costureira, do lar, doméstica, doceira, lavadeira, vendedora de doces e salgados, agente administrativa, auxiliar de higienização etc. Das dezoito casadas, seis moravam somente com o esposo. Com exceção destas e de duas que moravam sozinhas, todas as outras trinta e cinco, dividiam a moradia com filhos, marido e outros. Vinte mulheres (46,5\%) consideraram-se chefes de família, ou seja, responsáveis pelas decisões familiares. Com relação à cor auto referida, oito se identificaram como brancas; todas as outras trinta e cinco se denominaram negras, pardas e morenas.

\section{A experiência da dor vivenciada pelas mulheres infartadas}

A análise de dados permitiu a compreensão do significado da experiência da dor como sintoma prodrômico do IAM para mulheres e identificar as suas ações imediatas frente à mesma. A experiência está descrita da seguinte forma: a categoria central está representada em negrito e as categorias 
sob ela agrupadas, e que expressam a vivência dessa ruptura, estão representadas em itálico.

A categoria central que traduz e sintetiza o significado dessa experiência foi identificada como Tendo uma ruptura com a vida cotidiana. Esta se expressa com o rompimento repentino ou gradativo das mulheres com as ações características da vida cotidiana em virtude da dor ou do quadro de sinais e sintomas. Interagindo com a dor e os sintomas associados, as mulheres viram-se imobilizadas para realizar o que habitualmente faziam, sentiram-se atormentadas, perdendo gradativamente o controle da própria existência. Não conseguiram por si mesmas superar os desconfortos e manter o controle sobre as atividades habituais e, aos poucos ou de modo súbito, desenvolveram dependência de outras pessoas e da ação médica. Além disso, quase sempre recorreram a entidades divinas, crendo que poderiam livrá-las da dor e recuperar a vida.

O surgimento e a evolução dos sintomas prodrômicos do infarto, caracterizados pelas mulheres como incômodo, agonia, dor, cansaço ou falta de ar, foram determinando a cisão com as referências das ações cotidianas, à medida que perceberam que a resistência à dor e as condutas adotadas não conseguiam resolver o problema.

A partir da análise, foi possível identificar que o processo de ruptura com a vida cotidiana pode se dar de forma gradativa ou súbita, a depender da severidade da dor e dos sintomas associados.

Algumas mulheres vinham sentindo, há algum tempo, esses desconfortos. Embora suportáveis, interferiam em maior ou menor grau na realização das atividades rotineiras. Sentindo incômodos foi a categoria que expressou o aparecimento, a persistência ou o desaparecimento temporário da dor e/ou sintomas associados (cansaço, falta de ar, agonia etc.), indicando que algo não estava bem. Nesta fase, as mulheres não queriam se entregar à dor, pois se achavam fortes e resistentes e acostumadas a serem reconhecidas como tal.

Até aí eu já tinha sentido alguns problemas de palpitação. Quando eu subia ladeira, eu sentia pontadas no peito. (Rebeca) $^{(a)}$

Eu sentia essa dor direto, tinha dia que eu não podia nem dormir de dor. (Tina)

Elas perceberam as características da dor, a parte do corpo que doía, onde começava e para onde ela se estendia. A dor provocava dormência, apertava, estrangulava, queimava como fogo, ardia como pimenta, comprimia, pressionava, atravessava, furava ou rasgava o corpo.

(a) Todos os nomes das mulheres são fictícios.
Ela doía aqui em cima do peito, descia aqui para esse ombro, para o braço [...] Aí eu ficava o dia todinho com esse braço e esse ombro doendo. (Clara)

Essa dor foi uma dor assim, parecendo que estava pegando fogo, queimando mesmo por dentro sabe, aquele, aquele fogo enorme. (Joana)

Quando partilhavam a preocupação com vizinhas e familiares, relativizavam-na e postergavam a busca ao serviço de saúde e, com isso, a possibilidade de desarrumação da sua vida, da família e do cotidiano. Mas, em algum momento, os incômodos se acentuaram levando-as a interromper atividades rotineiras ou dominando-as, isto é, impossibilitando a realização da vida cotidiana. Outras mulheres não vivenciaram a fase dos incômodos, mas um episódio de dor súbita e crescente que provocava um sentimento de incapacidade.

Assim, experimentando uma ou outra trajetória, em algum momento, sentiram-se tomadas pela dor. Sendo dominadas pela dor foi a categoria que expressou a vivência da dor instaurando-se com grande magnitude e tornando-se duradoura. Assim, a dor, aos poucos ou abruptamente, restringia a ação, afetava não só o corpo, mas também a atividade mental. Essa dor paralisava o movimento físico, dificultava a fala, afetava o fôlego, relaxava esfíncteres, produzia náuseas e vômitos e, à medida que se intensificava e perdurava, imobilizava as mulheres, revelando a impotência pessoal no seu controle. Diante do agravo da dor, era inevitável negar que algo mais sério estava acontecendo, pois se sentiam impedidas de agir e viver o seu próprio modo de vida.

A dor que as dominava era de grande magnitude e violenta, provocando a sensação de que a pessoa ia explodir, estourar de tanta dor. Várias mulheres que associaram a dor à sentida no parto, a referiram como sendo pior e mais difícil de agüentar ou que nunca tinham vivido algo assim.

Porque a dor estava demais. Eu não pensei de ter uma dor daquela, nem a dor de ter um filho é uma dor daquela [...] A dor mais forte, foi a dor mais que eu senti; me doeu tudo aqui em cima do coração. (Lourdes)

Junto à dor, as mulheres vivenciaram alterações nas sensações e percepções do corpo, e no seu modo de funcionar habitualmente. Assim, a dor, gradativamente, as imobilizava. Relataram que a dor afetava o fôlego, vindo associada a cansaço, falta de ar e tosse. Sentiam-se abafadas e até mesmo sufocadas. Algumas mulheres tinham a sensação de desmaio ou mesmo desfaleciam; outras perdiam a força para falar. Diante desta dor, que se acentuava e se diferenciava, que afetava a autonomia e a capacidade de decidir, as mulheres sentiam-se fracas, perdendo a força e a capacidade para movimentar o corpo. Muitas não conseguiam mover as pernas e erguer os braços e muito menos andar. Algumas relataram que ficaram com as pernas e mãos adormecidas, precisando ser carregadas. 
Caminhava até de quatro para poder dar uma aliviada. Eu ficava sem fôlego, pelejava. Depois eu saía assim de quatro gritando, ai, ai, ai, para ver se o fôlego vinha e nada. (Adriana)

A dor veio forte e eu ficava deslembrada e sem sentido. (Angélica)

Junto à dor podiam experimentar náuseas e vômitos. Algumas sentiram que podiam urinar ou evacuar sem querer; outras se viram evacuadas e urinadas, sem ter conseguido controlar.

Passei a noite toda aqui com a dor, vomitei muito, mais que quatro vezes. (Terezinha)

Aquela dor que dá vontade de fazer xixi, fazer cocô, tudo ao mesmo tempo. (Esmeralda)

A vivência da dor foi revelando a perda da potência do corpo, da capacidade de perceber a si mesma e o meio que a cercava. Essa dor, que não cedia às tentativas de alívio feitas pelas mulheres, evidenciava também a impotência pessoal no seu controle. Ela era duradoura, persistente, ia piorando a cada instante e muito pouco ou nada do que faziam aliviava.

Aquela dor assim queimando e ai foi aumentando, aumentando, aumentando e, foi que me tomou toda, foi assim, só aumentando. Cada instante ela foi aumentando. (Alexandra)

As mulheres não suportavam a dor, não dava para agüentar, tolerar o seu massacre.

Eu não estava agüentando mais [...] É uma dor que, sinceramente, eu peço a Jesus que jamais volte sentir. (Ida)

Assim, se desesperaram. Então, se a dor afetava o corpo, e também perturbava a mente, as mulheres viram-se atormentadas por ela; isto é, sentiram-se desnorteadas, agoniadas, sem sossego, sem conseguir governar a própria vida.

Eu fiquei alucinada. Eu perdi o centro, perdi tudo. Eu não sabia nem quem eu era, eu não sabia nada. (Darci)

Algumas mulheres preferiam a morte à tortura da dor.

No dia que atacou, para eu ser internada, foi o dia que eu pedi: Deus, me joga lá da janela embaixo. (Rita)

Pode me matar doutor. Me mate, meu doutor, que eu não agüento mais. (Rosa)

Ao se sentirem dominadas pela dor, surgiu o medo de morrer como objeto de interação. Sentindo a vida em jogo foi a categoria que expressou o temor de perder a vida diante da dor. As mulheres perceberam que podiam morrer de dor; vivenciaram a sensação de morte iminente. Face à interação com a situação concreta de vulnerabilidade, emergiu o medo do desamparo da família, o temor de morrer e deixar os filhos, os netos, o companheiro e outros familiares sem o cuidado que costumavam dispensar. Pensaram na falta que podiam fazer e nas perdas afetivas que iriam ter. Apenas uma mulher relatou temor com as perdas no mundo do trabalho. Sentindo medo de morrer, o que mais queriam era se livrar da dor e recuperar a vida.

Pensei em meus filhos porque eles são dependentes de mim, muito dependentes mesmo, e aí eu pensei: Eu vou embora, e quem vai fazer, vai dar comida aos meus filhos? Quem vai fazer alguma coisa por eles? (Rose)

Meus filhos, deixar meus filhos. Eu pensei de morrer e deixar todo mundo. (Olga)

A minha preocupação era sair daquele quadro, passar a dor e ficar livre daquilo para cuidar da minha família. (Jaqueline)

A análise da experiência da dor como sintoma do infarto produziu um desconforto gigantesco nas mulheres, identificado pela categoria central: Tendo uma ruptura com a vida cotidiana.

A vida cotidiana é a vida de todo indivíduo. Nela são colocados em funcionamento todos os seus sentidos, as capacidades intelectuais, habilidades manipulativas (assimilação das relações sociais), sentimentos, paixões, idéias, ideologias $^{(11)}$.

[...] afastar-se da rotina cotidiana por deliberação própria representa uma escolha do indivíduo, assumindo caráter diferente de ser dela privado pela ação de forças indesejáveis ${ }^{(12)}$

Assim, romper involuntariamente com a vida cotidiana por uma condição do corpo é causa de desconforto, porque, geralmente, tem o sentido de impossibilidade de ser, no contexto de interação comum a todos os seres humanos.

Esta ruptura ou possibilidade de ruptura com a vida de todos os dias, causada pelos processos de adoecimento e morte, pode ser vivida de forma diferente por homens e mulheres, já que os modos de socialização entre os sexos são bastante diferenciados. Aos meninos, foi destinado o espaço da rua, dos brinquedos criativos, da liberdade de ir e vir, da vivência de uma sexualidade livre, que os prepara para assumir espaços públicos, postos de comando, uma vida diferenciada junto à casa e a família, quase sempre no papel de provedor. Mesmo que, a partir da década de 1980, as conquistas alcançadas com o movimento feminista tenham reposicionado estes espaços, as mulheres deste estudo foram socializadas, prioritariamente, para serem donas de casa, mães e esposas.

Educadas para o espaço privado da casa e da família, foram preparadas ao longo das suas vidas para serem boas esposas e mães e cuidarem do provimento da vida. Assim, diferente dos meninos, o cotidiano das brincadeiras na infância incluía as bonecas, a casinha, a vassoura, o ferro de 
engomar e tantos outros utensílios necessários ao trabalho doméstico. A função biológica da maternidade modela a sua vida social e vice-versa, produzindo e reproduzindo formas de compreensão do mundo, a partir do espaço privado. Há, portanto, diferentes formas de desagregação deste espaço quando mulheres em idade reprodutiva adoecem e/ou morrem. Se existem filhos menores e adolescentes, o fantasma do abandono, da separação dos membros da família, da marginalidade dos filhos está sempre presente.

Se estas mulheres são chefes de família, provedoras do sustento e não há ainda, por força da idade dos filhos, uma composição na renda salarial familiar, a possibilidade de afastamento por doença ou o desaparecimento provocado pela morte produz muita angústia e sofrimento. $\mathrm{O}$ fato de a família ser composta por adultos e as mulheres terem ultrapassado o período reprodutivo não produz necessariamente o desaparecimento deste quadro. Muitas mulheres deste estudo já eram avós, aposentadas, mas moravam com filhos, netos e noras que dependiam da sua aposentadoria e cuidado. A reorganização familiar nesta fase da vida pode produzir outros arranjos do cotidiano que mantém as mulheres permanentemente presas às teias da casa e da família: o sonho da independência econômica, o cuidado e o futuro dos netos, o suporte financeiro e afetivo dos filhos. Assim, nesta fase, o afastamento provocado pela doença e a interação com a finitude podem produzir o medo da dependência física e econômica, da desorganização familiar, da perda da liberdade de decidir sobre sua própria vida etc.

Mas o que as mulheres fizeram diante da dor? Sentindo incômodos ou Sendo dominadas pela dor, ou seja, tendo uma manifestação mais branda ou severa desse desconforto, resistiram a se entregar, tentando manter as atividades cotidianas. Todavia, quando imobilizadas e sentindo medo de morrer, o cotidiano foi relativizado e a dor tornou-se o principal objeto de interação.

A categoria Resistindo à dor expressou as tentativas das mulheres em sanar o mal que as afligia, recorrendo aos recursos pessoais. Situando-a no âmbito das fronteiras conhecidas, fizeram tentativas para melhorar. A princípio, resistiram à procura de socorro médico porque acreditavam no caráter passageiro da dor e preservavam a esperança de melhorar. Ainda, várias mulheres achavam que deveriam suportá-la. Em geral, elas não queriam se entregar à dor para não romper o fluxo espontâneo de ação da vida cotidiana. Enquanto suportaram, recusaram-se a aceitar os sintomas como extraordinários, banalizaram a dor e resistiram a acreditar que algo mais sério estava acontecendo. O desconhecimento da origem da dor e dos sintomas associados ajudou a potencializar a resistência à dor.

Eu esperei vinte dias pensando que era gases. Porque eu não gosto de ficar indo para o hospital assim por qualquer coisa. (Jussara)
Cheguei na porta da igreja esperando a noiva chegar para eu entrar com meu filho, aí tive aquela dor [...] e eu disse que ia levantar e ia na padaria beber água. Pegaram a cadeira para eu sentar até a dor aliviar e eu entrar na igreja [...] A noiva chegou no carro, a dor passou um pouco e eu entrei com ele. Entrei pedindo a Deus: meu Deus, eu quero ver o casamento do meu filho e eu quero entrar na igreja. (Aline)

Várias mulheres que vivenciaram apenas um evento doloroso, intenso e duradouro acreditaram que a dor era temporária e que nada mais grave estava acontecendo. Acreditaram que a melhora havia de chegar.

Para mim era uma dor no peito que ia passar com qualquer remédio. Chegava, tomava aquele remédio, aquela injeção ia passar. (Miriam)

As mulheres julgaram a dor e a maioria esmagadora não fez a sua associação a infarto ou a problema cardíaco. Definiram-na como mal-estar passageiro, problema de estômago ou pulmão, raiva, cólica, verme, bursite etc., ou mesmo não imaginaram o que era.

Eu não sabia que eu estava infartando, nem tampouco meus familiares tinham conhecimento. (Andréa)

Eu, na hora, não pensei que fosse coração [...] pensei que fosse um verme comendo meu estômago. (Ana)

Seis mulheres interpretaram a dor como sintoma cardiovascular, por já terem lido algo a respeito ou convivido com alguém que infartou. $\mathrm{O}$ fato de associarem a dor a problema cardíaco não significou ausência de resistência, pois fizeram tentativas, nem sempre acertadas, para melhorar.

Eu só pensei que era coração, mesmo porque eu sempre vejo falar. Meu marido também teve. (Bruna)

Algumas mulheres concebiam que dor é para ser tolerada, restando a elas gemer ou tentar aliviá-la com recursos próprios.

Eu fui suportando até que não deu mais. (Luíza)

Fiquei em casa sentindo muitas dores, até a hora que ela passou. Ficou doendo, doendo, doendo até que era para ela parar. Ela ia ficando mais fraca, aí parava e eu ficava toda dolorida, pescoço, ombro, braço. (Célia)

Várias tentativas para melhorar foram feitas, baseadas na interpretação dada à dor. Assim, crendo que estava associada a problema de estômago ou pulmão, bursite, pressão alta, entre outros, decidiram tomar chás e remédios conhecidos, adotaram posições para aliviar, repousaram.

Tentei tomar um chá para ver se melhorava. Quando eu vi que nada resolvia, fiquei esperando para ver se melhorava. (Joanira) 
Suportando a dor, não conhecendo a natureza real dos sintomas, esperando melhorar e fazendo tentativas para melhorar, algumas retardaram a consideração da gravidade de sua condição e a busca de atenção médica. Admitir a necessidade de socorro médico era considerar a possibilidade de cisão com a vida cotidiana.

Eu ainda não queria ir pro hospital. Ele insistiu, aí eu fui. (Janilde)

Sentia aquela dor, as minhas filhas sempre diziam: Vá ao médico. Não, mas eu nunca ia, só fui mesmo quando tive o infarte. (Vera)

A categoria Resistindo à dor mostrou que a ação das mulheres em face da dor e dos sintomas associados foi, a princípio, de resistência; procuraram suportá-la, aliviá-la, esperaram melhorar e não quiseram, de imediato, se entregar ao socorro médico.

Esse processo de resistência revela que aceitar a impossibilidade de controle pessoal sobre a dor e os sintomas é imaginar ou sucumbir à ruptura com os padrões usuais da vida cotidiana ${ }^{(12)}$. Portanto resistir à dor é uma estratégia para se manter no cotidiano, no lugar em que se constitui como unidade, como indivíduo que reproduz, de modo particular, as características básicas da sociedade. Portanto a ruptura forçada e abrupta com o cotidiano pelo infarto exerce um grande impacto na vida das pessoas, pois um indivíduo engajado socialmente, envolvido com a rotina diária, trabalhando, relacionando-se, de repente se vê obrigado a se afastar do palco dessas interações e a enfrentar dificuldades em diferentes dimensões da vida ${ }^{(12)}$. Assim, essa

ruptura implica interromper e fragmentar interações que dão sentido à existência, atividades, relações, pensamento e ação, para focar a atenção sobre uma condição específica $^{(12)}$.

Se no exercício de seus papéis na vida cotidiana a mulher constrói enfrentamento e resistência, também se viu a presença desse comportamento face à dor como forma de manter o controle da própria existência. Vale ressaltar que a socialização diferenciada em função do sexo promove formas de convivência diferenciadas entre homens e mulheres. A reprodução social da vida delimita, constrói e reconfigura os espaços, dando às mulheres maior possibilidade de compartilhar e socializar as suas experiências. Assim, verdadeiras redes sociais são criadas (familiares, de amigas, de vizinhança) e maneiras de enfrentamento individuais e coletivos se formam para resolver os problemas do cotidiano, que vão desde a formação das associações de bairro para problemas que demandam políticas públicas, água, saneamento, habitação e outros, como agrupamentos de vizinhança para socializar o cuidado com os filhos. Há, portanto, neste processo socializatório, modos de produzir enfrentamento e resistência ${ }^{(13)}$. A análise das falas das mulheres, a partir das categorias, permitiu verificar-se a configuração deste processo frente à dor.
Se, por um lado, as redes sociais e formas de enfrentamento individuais e coletivas se dão de modo positivo para resolver problemas do cotidiano, de outro, a resistência à dor implica em risco de vida e incapacidades geradas pelo infarto, pois o retardo na procura de atendimento médico-hospitalar pode impedir que sejam beneficiadas pelas terapias de reperfusão coronariana que reduzem a morbimortalidade pela doença ${ }^{(4)}$. Para diminuir esse retardo, entretanto, são necessárias ações integradas da equipe de saúde sobre os fatores envolvidos na resistência, visando transformá-la em uma ação que resulte em benefício para as mulheres. É necessário pensar em estratégias que mobilizem, em especial, pessoas de maior risco e próximas a elas, no sentido de valorizar a busca imediata de atendimento médico diante da dor como sintoma do infarto.

Se a duração da resistência à dor foi influenciada pelos fatores anteriormente mencionados, a sua paralisação ocorreu em face da dor crescente e insuportável, da impotência no seu controle e do medo de morrer. Nessa situação, as mulheres viram-se dependentes de socorro para ter a vida de volta. A intensidade com que a dor imobilizava influenciou na rapidez com que decidiram pedir ajuda e procurar atendimento.

Dependendo de socorro externo para ter a vida de volta foi a categoria que expressou a aflita busca de ajuda para aliviar ou sanar a dor e recuperar a vida que ficou pendente. Diante da dor crescente, as mulheres não podiam ser mais sujeitos ativos da vida cotidiana; a dor ameaçava e suspendia a vida cotidiana. Agora, só outras pessoas podiam fazer alguma coisa por elas; a garantia da sobrevivência dependia da ação de outros. O controle da dor passou a ser externo a elas mesmas. Viram-se dependentes da ajuda de pessoas próximas, de Deus e da ação médica.

Imobilizadas pela dor, gritaram por socorro e receberam ajuda de familiares, amigos, estranhos e vizinhos. Perceberam-se sendo ajudadas a providenciar o transporte e sendo levadas ao socorro médico, tendo apoio para suportar a dor, ajuda para andar, levantar, vestir-se etc. Às vezes foram carregadas. As pessoas prepararam chás ou providenciaram algum medicamento para tomar.

Pedi a menina para ligar para um rapaz que morava em baixo [...] para ele vir me socorrer. (Neusa)

Eu disse: Minha gente me dê um socorro que eu vou morrer. (Antônia)

A maioria das mulheres esperava pela salvação divina; que um ser Superior as livrasse do mal que estava arrebatando a vida. Contavam com receber força divina e ter a vida concedida por mais tempo.

Eu confio em Deus todo poderoso né? Eu confio nele, Jesus, e eu creio que ele me libertou e não me deixou morrer. É um Deus muito bom, muito maravilhoso. (Paloma) 
Só pedindo muita proteção a Deus. Só ele, mais ninguém pode fazer isso por a gente. (Luana)

Elas queriam, sobretudo, que o médico resolvesse a dor. Portanto depositaram no saber médico o alívio da dor, o resgate da vida. $\mathrm{O}$ caminho trilhado pelas mulheres, ao decidirem procurar atendimento médico, foi associado à intensidade dos incômodos. Interagindo com os incômodos toleráveis, mas suspeitando que algo não estava bem, pois não conseguiram solucionar a dor com os recursos pessoais, a ação foi marcar e ir à consulta médica. Na condição de dominadas pela dor, a maioria correu para um local de atendimento. Outras fizeram contato telefônico com o médico ou chamaram uma ambulância em seu domicílio. Independente do caminho percorrido, seja na forma de consulta, seja na corrida a socorro médico, confrontaram-se com a necessidade da intervenção médica porque almejavam se livrar da dor e recuperar a vida.

Bem, claro eu senti, principalmente, necessidade de médi$\mathrm{co}$, né? Alguém que me socorresse naquele momento [...] é muito ruim. (Jurema)

Não hora da dor fui ao médico para me livrar, para me livrar daquela hora, daquela dor. (Elisabete)

Ficando com a potência de agir freada, bloqueada pela ação de forças exteriores - os efeitos da doença no corpo e na alma - que lhe retiram a autonomia para agir e pensar, as pessoas perdem a espontaneidade característica da vida cotidiana, tornando-se dependentes de outros ${ }^{(12)}$.

As mulheres que antes governavam suas vidas no cotidiano, agora dependem de uma ação externa para combater o mal que as aflige. Colocar o controle da existência em uma potência externa a si mesma é, por si só, fonte também de medo.

\section{CONSIDERAÇÕES FINAIS}

A experiência da dor como sintoma prodrômico do infarto do miocárdio vivenciada pelas mulheres revelou o desconforto provocado pela ruptura com a vida cotidiana. A única forma de evitá-lo é com a prevenção do próprio infarto. $\mathrm{Na}$ prevenção da doença arterial coronariana, em especial no que se refere à identificação e ao controle de fatores de risco, a enfermeira pode atuar em diversos níveis, para que as pessoas não cheguem a ponto de romper com a vida que dá sentido à existência, a vida de todos os dias ${ }^{(14)}$.

O estudo também mostrou o risco de vida a que as mulheres se submetem com as ações de resistência à dor. Considerando que 40 a $60 \%$ das mortes por doença arterial coronariana ocorrem na primeira hora após o início dos sintomas $^{(4)}$, o retardo da decisão de buscar atenção médica precisa ser minimizado. Portanto a enfermeira pode atuar no plano simbólico das mulheres, visando conscientizá-las do maior risco de vida ao tentarem manter as atividades cotidi- anas frente aos sintomas do infarto. As mulheres precisam ser alertadas de que resistir à ruptura com a vida cotidiana diante da dor pode significar o risco de perdê-la ou limitá-la permanentemente.

A enfermeira pode atuar na educação à saúde de pessoas com risco potencial para infarto do miocárdio, seus familiares e a comunidade em geral (prédios públicos, ambientes de trabalho, escolas etc.), com vistas à conscientização sobre os sinais e sintomas eminentes do infarto e da importância do socorro médico imediato em face da dor ${ }^{(4)}$. Mas, se ações de sobrevida são essenciais por parte das mulheres e pessoas próximas a elas, também é verdade que precisam dispor de um serviço médico de emergência com protocolos de atendimento e cuidado precoce ao ataque cardíaco adequados ao enfrentamento do infarto do miocárdio ${ }^{(4,14)}$.

A investigação propiciou ainda reflexões sobre as possibilidades do uso de gênero como categoria analítica para compreensão de problemas de saúde específicos de homens e mulheres. A construção social sobre os papéis das mulheres identifica a maternidade historicamente associada à presença da dor e do sofrimento. A passagem por esta prova biológica juntamente com a experiência de ser mãe (com todas as dores para criar e enfrentar a perda do convívio com os filhos), associou a imagem das mulheres à capacidade de suportar física e psicologicamente as dores, em muitas culturas. Assim, o ideal de feminilidade foi construído a partir de estereótipos que conformavam as mulheres como dóceis, frágeis, sensíveis, mas com infinita capacidade para serem pacientes e suportarem as dores e as adversidades provocadas pelos processos de adoecimento e perdas. Deste modo, tender-se-ia a afirmar que há diferenças nas formas ou razões de homens e mulheres encararem as dores e, consequientemente, buscarem serviços de saúde para o seu alívio.

Nos estudos epidemiológicos, o uso do gênero como categoria analítica para a compreensão do processo saúdedoença só se deu na década de 1990. Assim, a inclusão deste enfoque como ferramenta analítica vem enriquecendo os marcos teóricos explicativos dos processos de saúde e adoecimento ao identificar fatores que, isolados ou associados, podem revelar necessidades especiais de atenção à saúde, riscos específicos de adoecer e morrer ligados a tarefas ou atividades definidas como masculinas e femininas. A categoria gênero, como ferramenta analítica, pode ainda revelar percepções culturalmente construídas por mulheres e homens sobre as doenças e suas formas de tratamento, condutas diferenciadas de ambos os sexos para buscarem atenção à saúde, diferenças de tratamento e cuidado realizados pelos profissionais de saúde em função do sexo e tantos outros $^{(15)}$.

Assim, justifica-se plenamente a incorporação deste conceito no estudo de problemas específicos, como a dor no infarto, pois pesquisas realizadas em outros países e no Bra- 
sil revelaram que o tratamento do infarto nas mulheres foi significativamente mais tardio que nos homens, já que os sintomas não foram devidamente valorizados por elas e pelos profissionais que as atenderam ${ }^{(16)}$.

Estudo realizado há aproximadamente 20 anos já identificou tendência de alguns médicos em considerar que as mulheres exageram ao relatar sintoma de adoecimento e, por isso, os fatores psicológicos teriam um papel fundamental no aparecimento das mesmas ${ }^{(16)}$.

Para explicar a construção sociocultural das diferenças e desigualdades entre mulheres e homens, o que configura o conceito de gênero, as teóricas feministas têm trilhado vários caminhos, ainda que todas considerem a opressão das mulheres o ponto central que explica o desenvolvimento das sociedades humanas. Duas premissas norteiam as teorias de gênero: o reconhecimento de que o equipamento biológico sexual inato não dá conta da explicação do comportamento diferenciado masculino e feminino observado na sociedade; o poder é distribuído de modo desigual, cabendo às mulheres uma posição subalterna na organização da vida social ${ }^{(17)}$.

\section{REFERÊNCIAS}

(1) Laurenti R, Buchalla CM, Caratin CVS. Doença isquêmica do coração. Internações, tempo de permanência e gastos. Brasil, 1993 a 1997. Arq Bras Cardiol. 2000;74(6):483-7.

(2) Lessa I. Perfil das doenças cardiovasculares no Brasil. In: Mion Júnior D, Nobre F, editores. Risco cardiovascular global. São Paulo: Lemos; 1999. p. 15-30.

(3) Passos LCS. Gênero e letalidade hospitalar das síndromes coronarianas agudas em Salvador-Bahia [tese]. Salvador: Universidade Federal da Bahia; 2000.

(4) Potsch AA, Bassan R. O atendimento e o tratamento préhospitalar do infarto agudo do miocárdio. In: Timmerman A, Feitosa GS, editores. Síndromes coronárias agudas. Rio de Janeiro: Atheneu; 2003. p. 231-42.

(5) American Heart Association (AHA). Suporte básico de vida para profissionais de saúde. Buenos Aires: Waverly Hispanica; 2002.

(6) Bahr RD. Access to early cardiac care: chest pain as a risk factor for heart attacks, and the emergence of early cardiac care centers. Maryland Med J. 1992;42(2):133-8.

(7) Bahr RD. Reawakening awareness of the importance of prodomal symptoms in the shifting paradigm to early heart attack care. Clinician. 1996;14(4):7-9.

(8) Glaser BG. Theoretical sensitivity. California: Sociology Press; 1978.

(9) Charon JM. Simbolic Interactionism. $3^{\text {rd }}$ ed. Englewood Cliffs: Prentice-Hall; 1989.

(10) Slabi RA, Solimene MC, Luz PL, Benjó AM, Lemos Neto PA, Ramires JAF. Comparação entre homens e mulheres jovens com infarto do miocárdio. Arq Bras Cardiol. 2002;75(5):510-7.
Os estudos de gênero, dentre os muitos benefícios que trouxeram à sociedade e de forma mais direta à mulher, deram visibilidade à maternidade como papel definidor da condição das mulheres e possibilitaram a redefinição de novos espaços sociais. Os estudos têm também servido para ampliar o conceito de saúde, a noção de saúde sexual e reprodutiva, a visibilização da violência de gênero, questões de discriminação dos espaços de trabalho, estudos das doenças sexualmente transmissíveis, incluindo HIV/AIDS, dentre outros temas ${ }^{(18)}$. Mesmo assim, até o presente, apesar de todo o desenvolvimento tecnológico e dos processos políticos para diminuir as desigualdades de gênero, as raízes culturais e os processos sociais de reprodução de estereótipos e desigualdades são fortemente presentes na cultura brasileira. No que se refere à vivência da dor no infarto agudo do miocárdio, o campo de análise a partir da categoria gênero é ainda incipiente e o afrofundamento das pesquisas poderão trazer grandes benefícios para a prevenção da morbi-mortalidade da doença.

(11) Heller A. O cotidiano e a história. $3^{\mathrm{a}}$ ed. Rio de Janeiro: Paz e Terra; 1992.

(12) Mussi FC. Padecendo a perda da espontaneidade da ação: o desconforto vivenciado por homens que sofreram infarto agudo do miocárdio [tese]. São Paulo: Escola de Enfermagem da USP; 2000.

(13) Souza VLC. A violência conjugal e sua influência na decisão da mulher pelo aborto [dissertação]. Salvador: Universidade Federal da Bahia; 2000.

(14) Mussi FC, Koizumi MS, Angelo M, Lima MS. Padecendo a perda da espontaneidade da ação: o desconforto vivenciado por homens que sofreram infarto agudo do miocárdio. Rev Esc Enferm USP. 2002;36(2):115-24.

(15) Ferreira SL, Nascimento ER, Paiva MS. Reflexões teóricometodológicas sobre o conceito de gênero aplicado à pesquisa em enfermagem. In: Anais do $12^{\circ}$ Seminário de Pesquisa em Enfermagem; 2003 abr. 27-30; Porto Seguro. Porto Seguro: Centro de Convenções; 2003.

(16) Armitage KJ, Schneiderman LJY, Bass RA. Response of physicians to medical complaints in men and women. JAMA. 1979;241(20):186-7.

(17) Sorj B. O feminismo na encruzilhada da modernidade e pósmodernidade. In: Costa AO, Bruschini C, organizadores. Uma questão de gênero. Rio de Janeiro: Rosa dos Tempos; 1992. p. 15-23.

(18) Correa S. Gênero e saúde: campo de transição. In: Bruschini C, Unbehaum S, organizadoras. Gênero, democracia e sociedade brasileira. São Paulo: FCC/ Editora 34; 2000. p. 357-88. 